\title{
Carboxyhaemoglobin levels of smokers and non-smokers working in the City of London
}

\author{
C. M. CASTLEDEN ${ }^{1}$ and P. V. COLE \\ Anaesthetics Laboratory, St. Bartholomew's Hospital, London EC1A 7BE
}

\begin{abstract}
Castleden, C. M. and Cole, P. V. (1975). British Journal of Industrial Medicine, 32, 115-118. Carboxyhaemoglobin levels of smokers and non-smokers working in the City of London. The carboxyhaemoglobin (COHb) levels of two groups of workers in the City of London were determined. The mean $\mathrm{COHb}$ in smokers $(5.8 \%)$ was significantly greater than that of the non-smoking group $(1 \cdot 3 \%)$. In general, cigarette consumption could be directly related to the $\mathrm{COHb}$ level but there was considerable individual variation. The mean $\mathrm{COHb}$ level of manual workers was significantly lower than that of sedentary workers even though the former group tended to smoke more heavily.
\end{abstract}

The association between smoking and cardiovascular disease in man is now well established (Royal College of Physicians Report, 1971; Report of the Surgeon General, 1971). Hitherto nicotine was believed to be the main constituent in cigarette smoke affecting the cardiovascular system, even though increased blood levels of nicotine have never been directly demonstrated in man. More recently carbon monoxide (CO), a constituent of tobacco smoke, has been more closely examined for its role in causing some of the pathological conditions known to be associated with smoking. Tobacco smoke contains up to $5 \%$ CO (Wynder and Hoffman, 1967) which when inhaled combines with haemoglobin to form a stable compound, carboxyhaemoglobin $(\mathrm{COHb})$. This compound interferes with oxygen carriage by the blood in two ways. First it has the effect of decreasing the amount of haemoglobin available for oxygen carriage, and secondly there is a less wellknown effect of increasing the oxygen affinity of the remaining oxyhaemoglobin so that oxygen is given up to the tissues less readily than normally. This is described as a 'shift to the left' of the haemoglobin dissociation curve and has been shown to occur in subjects who smoke (Birnstingl, Cole, and Hawkins, 1967).

In the experimental animal Astrup (1972) and

${ }^{1}$ Present address: Geriatric Department, Southampton General Hospital, Tremona Road, Southampton SO9 4XY
Kjeldsen, Astrup, and Wanstrup (1972) have shown that cholesterol fed rabbits breathing carbon monoxide in sufficient quantity to raise the $\mathrm{COHb}$ to about $17 \%$ have more atheroma in the aorta than those breathing air. In man, with levels of $5-10 \%$ $\mathrm{COHb}$, Ayres, Giannelli, and Mueller (1970) found that the coronary arteriovenous oxygen difference decreased while coronary blood flow increased, probably indicating that the myocardium was insufficiently oxygenated, and at $\mathrm{COHb}$ levels of $14 \%$, they detected a decrease in arterial and mixed venous oxygen tension. Ayres et al. (1970) further showed that some patients with coronary artery disease developed altered lactate and pyruvate metabolism following an increase in their $\mathrm{COHb}$ levels, again suggesting a degree of myocardial hypoxia. The falls in oxygen tension found by Ayres et al. (1970) have been explained by the fact that $\mathrm{COHb}$ not only shifts the curve to the left but also changes its shape from the normal sigmoid towards that of a rectangular hyperbola (Haldane, 1912). This results in a subsequent increase of the effect of any existing venous admixture to the arterial circulation (Brody and Coburn, 1969; 1970). Chevalier, Krumholz, and Ross (1966) demonstrated that the degree of oxygen debt induced in smokers after exercise could be simulated in non-smokers if they had previously inhaled carbon monoxide. Thus it is possible that tobacco angina previously thought to be 
due to catecholamine release (Oram and Sowton, 1963) may in fact be caused by raised COHb levels resulting in myocardial hypoxia.

Recent work has demonstrated the correlation between $\mathrm{COHb}$ levels and smoking, and that smokers who inhale have far higher levels than nonsmokers (Cole, Hawkins, and Roberts, 1972; Russell, Cole, and Brown, 1973a; Castleden and Cole, 1973), but the relationship between occupation, smoking, and $\mathrm{COHb}$ levels in the population at large is at present unknown.

Goldsmith and Landaw (1968) have correlated the smoking habits of 3311 longshoremen with their $\mathrm{COHb}$ levels. These blood levels were estimated indirectly by measurement of the carbon monoxide concentration in expired air. If the direct estimation of blood $\mathrm{COHb}$ is a good indication of inhalation of smoke, it can provide physicians with the certain knowledge that a patient is at risk from smoking. However, it is first necessary to establish the $\mathrm{COHb}$ level in the average subject. We therefore report the results of a survey carried out in the City of London in sedentary and manual workers.

\section{Method}

Two groups of subjects were studied towards the erd of their working day-manual workers (Smithfield meat porters) and sedentary workers (City office workers, the majority of whom were blood donors). Samples of venous blood were taken into heparinized syringes, capped and iced, and analysed for $\mathrm{COHb}$ on the same day by means of a CO Oximeter (Instrumentation Laboratories 1 Model 182) (Russell et al., 1973a). Some estimations were duplicated by means of the method of Commins and Lawther (1965) to ensure accuracy (Commins and Lawther, 1965; Lily, Cole, and Hawkins, 1972). Each subject completed a short questionnaire on his smoking habits. Twenty spot samples of the atmosphere breathed by each group were taken, dried, and analysed for $\mathrm{CO}$ on a Uras $2 \mathrm{CO}$ analyser (Hartmann and Braun).

\section{Results}

As the variance of the mean $\mathrm{COHb}$ tended to increase with the level of smoking, the data were transformed logarithmically and the resulting standard deviations were reasonably constant (Table 1).
TABLE 1

\begin{tabular}{l|cccc}
\multicolumn{4}{c}{ SMOKING GrouP-LOG COHb\% } \\
\hline & \multicolumn{4}{|c}{ No. of cigarettes/day } \\
\cline { 2 - 5 } & 0 & $1-10$ & $11-20$ & $>20$ \\
\hline $\begin{array}{l}\text { Mean } \\
\text { Standard }\end{array}$ & 0.079 & 0.523 & 0.767 & 0.794 \\
\hline deviation & 0.23 & 0.24 & 0.20 & 0.16 \\
\hline
\end{tabular}

The results were compared statistically by means of a two-way analysis of variance, and standard errors of group means of the transformed data were estimated from the residual mean square in the analysis of variance.

Manual workers had a different daily consumption of cigarettes compared to sedentary workers. The largest group of manual workers $(42.9 \%)$ smoked more than 20 cigarettes per day whereas the majority of sedentary workers $(58.4 \%)$ smoked between 11 and 20. However, even though they smoked more, on average the mean $\mathrm{COHb}$ level of the manual workers was significantly lower than that of the sedentary workers (Table 2).

There is a highly significant difference between the mean $\mathrm{COHb}$ level of all non-smokers $(1.3 \%)$ and those smoking 1-10 cigarettes per day $(3 \cdot 8 \%)$. The difference is also highly significant between the mean $\mathrm{COHb}$ level of those smoking 1-10 cigarettes per day and 11-20 per day, but there is no difference between the two heaviest smoking groups, i.e., 11-20 and more than 20 per day (Table 3 ).

The mean $\mathrm{COHb}$ level of the non-smoking sedentary workers did not differ significantly from that of the manual workers despite the fact that the atmospheric carbon monoxide was higher for the manual workers (mean $10.3 \mathrm{ppm}$, range $8-16 \cdot 5$ ) than for the sedentary workers (mean $6.7 \mathrm{ppm}$, range 3-8).

Three out of 204 non-smokers $(1.5 \%)$ had a $\mathrm{COHb}$ level above $2.5 \%$, and a value of zero was not recorded in any subject. Of the smokers $5.7 \%$ have $\mathrm{COHb}$ levels in the range found in non-smokers.

TABLE 2

Comparison of COHb LeVels of the Two TyPes of OCCUPATION

\begin{tabular}{|c|c|c|c|c|c|c|c|}
\hline \multirow{2}{*}{ Occupation } & \multirow{2}{*}{$\begin{array}{c}\text { Number } \\
\text { of } \\
\text { subjects }\end{array}$} & \multicolumn{3}{|c|}{ Mean $\mathrm{COHb} \%$} & \multirow{2}{*}{$\begin{array}{c}\text { Log mean } \\
\text { of } \\
\text { total COHb }\end{array}$} & \multirow{2}{*}{$\begin{array}{l}\text { Standard } \\
\text { error of } \\
\quad \log \end{array}$} & \multirow{2}{*}{$\begin{array}{c}\text { Difference } \\
\text { in } \\
\text { log mean }\end{array}$} \\
\hline & & Smokers & Non-smokers & Total & & & \\
\hline $\begin{array}{l}\text { Sedentary } \\
\text { Manual }\end{array}$ & $\begin{array}{r}318 \\
97\end{array}$ & $\begin{array}{l}6 \cdot 1 \\
5 \cdot 0\end{array}$ & $\begin{array}{l}1 \cdot 3 \\
1 \cdot 5\end{array}$ & $\begin{array}{l}2 \cdot 9 \\
3 \cdot 8\end{array}$ & $\begin{array}{l}0.378 \\
0.463\end{array}$ & $\begin{array}{l}0.012 \\
0.022\end{array}$ & \\
\hline
\end{tabular}

***Significant at $1 / 1000$ level 
TABLE 3

Comparison of COHb LeVels of the SMOKING Groups

\begin{tabular}{c|c|c|c|c|c}
\hline $\begin{array}{c}\text { Number of } \\
\text { cigarettes smoked } \\
\text { each day }\end{array}$ & $\begin{array}{c}\text { Number of } \\
\text { subjects }\end{array}$ & Mean COHb\% & $\begin{array}{c}\text { Mean of } \\
\text { sum of } \\
\text { logs }\end{array}$ & $\begin{array}{c}\text { Standard } \\
\text { of logs }\end{array}$ & $\begin{array}{c}\text { Difference } \\
\text { in log } \\
\text { mean }\end{array}$ \\
\hline 0 & 204 & $1 \cdot 3$ & 0.079 & 0.015 & $0.443 * * * *$ \\
$1-10$ & 59 & 3.8 & 0.523 & 0.028 & $0.244 * * *$ \\
$11-20$ & 101 & $6 \cdot 1$ & 0.767 & 0.021 & $0.027 \mathrm{~ns}$ \\
$>20$ & 51 & 6.7 & 0.794 & 0.030 & \\
\hline
\end{tabular}

****Significant at $1 / 10000$ level

ns $=$ Not significant

\section{Discussion}

According to national figures, $65-70 \%$ of men are smokers (Royal College of Physicians Report, 1971). However, in our study the total number of smokers was approximately equal to that of the non-smokers. An explanation for our figures is that only $44 \%$ of the blood donors were smokers compared to $65 \%$ of the manual workers and $70 \%$ of the office workers who were not blood donors. Hence there are many more non-smokers among blood donors than are found in the general population.

Following a survey involving 3311 longshoremen Goldsmith and Landaw (1968) reported a correlation between the number of cigarettes smoked and the $\mathrm{COHb}$ level which they had calculated from the $\mathrm{CO}$ in their expired air. They found a mean level of $6.8 \%$ in those smoking two 'packs of cigarettes' per day, of $5.9 \%$ in those smoking $\frac{1}{2}-2$ packs per day, and $3.8 \%$ if they smoked less than $\frac{1}{2}$ 'a pack a day'. We too have found that the mean $\mathrm{COHb}$ level tends to increase with the number of cigarettes per day, but that this trend was only statistically significant between groups 1-10 and 11-20 (Table 3).

A comparison between the two types of workers shows that there are highly relevant differences. The mean $\mathrm{COHb}$ level of manual workers is significantly lower than that of sedentary workers even though the manual workers tend to smoke more heavily.

An explanation for these findings might be that either the manual worker does not inhale the smoke of his cigarettes to such an extent as the sedentary worker or that he is eliminating the accumulated carbon monoxide at a quicker rate. We know of no evidence that manual workers smoke their cigarettes in a different manner from other people, but there are several reports that an increase in the rate of fall of $\mathrm{COHb}$ levels can be achieved by hyperventilation and by exercise (Forbes, Sargent, and Roughton, 1945; Coburn, Forster, and Kane, 1965; Shields, 1971).

The manual workers were Smithfield meat-porters and hence fitter and more active than the sedentary group who worked in offices. The significantly lower
$\mathrm{COHb}$ levels of the meat-porters who smoke compared to the other group of smokers can therefore be explained by the relatively increased alveolar ventilation inherent in their occupation. This will result in an increased elimination of carbon monoxide, thereby maintaining their $\mathrm{COHb}$ at a lower level.

A comparison of the levels of $\mathrm{COHb}$ found in smokers (mean $5.8 \%$ ) with that of non-smokers (mean $1.3 \%$ ) breathing city air shows that cigarette smoke is a far more potent elevator of $\mathrm{COHb}$ than any other form of air pollution in normal circumstances. Two investigators have attempted to show the effects of comparatively high levels of carbon monoxide produced from car exhaust on $\mathrm{COHb}$ levels in non-smokers. Lawther and Commins (1970) measured $\mathrm{COHb}$ levels in policemen after about three hours on point duty. Eight were non-smokers and 17 were smokers. The mean $\mathrm{COHb}$ level was $1.9 \%$ in the non-smokers, compared to $1.3 \%$ in our subjects, and $3.6 \%$ in the smokers. Jones, Commins, and Cernik (1972) found a difference between the $\mathrm{COHb}$ levels of non-smoking taxi-drivers on day duty (mean $2.3 \%$ ) and those on night duty (mean $1.0 \%$ ). Both these authors concluded that the effect of smoking on $\mathrm{COHb}$ levels outweighed that of exposure to street air. Goldsmith and Landaw (1968) tried to minimize the effect of community pollution in their longshoremen by taking samples before work, but the calculated mean $\mathrm{COHb}$ level in non-smokers $(1 \cdot 2 \%)$ was only $0.1 \%$ below that of our subjects who had been exposed to city air for at least six hours.

Eighteen of our smokers $(5.7 \%)$ had low $\mathrm{COHb}$ levels, that is, similar to the levels found in nonsmokers. In 12 of these it is known that they smoked within four hours of blood being taken. The average increase in $\mathrm{COHb}$ level in the blood of inhalers following a cigarette is $1-1.5 \%$ (Russell et al., 1973b) and the half-life of $\mathrm{COHb}$ during light activity is between two and four hours (Castleden and Cole, 1974). Hence we conclude that a small percentage of cigarette smokers do not inhale.

In conclusion, although the exact role of carbon 
monoxide in causing disease in man is as yet uncertain the estimation of $\mathrm{COHb}$ is a positive indication first of the degree of inhalation of tobacco smoke with all its constituents, and therefore, secondly the degree of risk to the subject of any subsequent disease whatever the mechanism. The difference in the $\mathrm{COHb}$ levels that occurs between smokers and non-smokers is so marked that an inhaling smoker can easily be recognized. If a physician advises a patient to stop smoking, a subsequent estimation of his $\mathrm{COHb}$ will be an absolute indication of whether or not the patient had heeded his advice.

We wish to thank S. V. Lincoln, B.Sc., F.I.S., from the Mathematics Department, Portsmouth Technical College for his help with the statistical analysis.

\section{References}

Astrup, P. (1972). Some physiological and pathological effects of moderate carbon monoxide exposure. British Medical Journal, 4, 447-452.

Ayres, S. M., Giannelli, S. Jr., and Mueller, H. (1970). Myocardial and systemic responses to carboxyhaemoglobin. Annals of the New York Academy of Sciences, 174, 268-293.

Birnstingl, M., Cole, P., and Hawkins, L. (1967). Variations in oxyhaemoglobin dissociation with age, smoking and Buerger's disease. British Journal of Surgery, 54, 615-617.

Brody, J. S. and Coburn, R. F. (1969). Carbon monoxideinduced arterial hypoxemia. Science, 164, 1297-1298. - and - (1970). Effects of elevated carboxyhemoglobin on gas exchange in the lung. Annals of the New York Academy of Sciences, 174, 255-260.

Castleden, C. M. and Cole, P. V. (1973). Inhalation of tobacco smoke by pipe and cigar smokers. Lancet, 2, 21-22.

and - (1974). Variations in carboxyhaemoglobin levels in smokers. British Medical Journal, 4, 736-738.

Chevalier, R. B., Krumholz, R. A., and Ross, J. C. (1966). Reaction of non-smokers to carbon monoxide inhalation. Cardiopulmonary responses at rest and during exercise. Journal of the American Medical Association, 198, 1061-1064.

Coburn, R. F., Forster, R. E., and Kane, P. B. (1965). Considerations of the physiological variables that determine the blood carboxyhemoglobin concentration in man. Journal of Clinical Investigation, 44, 1899-1910.

Cole, P. V., Hawkins, L. H., and Roberts, D. (1972). Smoking during pregnancy and its effect on the fetus. Journal of Obstetrics and Gynaecology of the
British Commonwealth, 79, 782-787.

Commins, B. T. and Lawther, P. J. (1965). A sensitive method for the determination of carboxyhaemoglobin in a finger prick sample of blood. British Journal of Industrial Medicine, 22, 139-143.

Forbes, W. H., Sargent, F., and Roughton, F. J. W. (1945). The rate of carbon monoxide uptake by normal men. American Journal of Physiology, 143, 594-608.

Goldsmith, J. R. and Landaw, S. A. (1968). Carbon monoxide and human health. Science, 162, 1352-1359.

Haldane, J. B. S. (1912/1913). The dissociation of oxyhaemoglobin in human blood during partial $\mathrm{CO}$ poisoning. Journal of Physiology, 45, xxii.

Jones, R. D., Commins, B. T., and Cernik, A. A. (1972). Blood lead and carboxyhaemoglobin levels in London taxi drivers. Lancet, 11, 302-303.

Kjeldsen, K., Astrup, P., and Wanstrup, J. (1972). Ultra-structural intimal changes in the rabbit aorta after a moderate carbon monoxide exposure. Atherosclerosis, 16, 67-82.

Lawther, P. J. and Commins, B. T. (1970). Cigarette smoking and exposure to carbon monoxide. Annals of the New York Academy of Sciences, 174, 135-147.

Lily, R. E. C., Cole, P. V., and Hawkins, L. H. (1972). Spectrophotometric measurement of carboxyhaemoglobin. British Journal of Industrial Medicine, 29, 454457.

Oram, S. and Sowton, E. (1963). Tobacco angina. Quarterly Journal of Medicine, 32, 115-143.

Report of the Surgeon General, U.S.A. (1971). The Health Consequences of Smoking. Washington, Dept. of Health, Education and Welfare.

Royal College of Physicians Report (1971). Smoking and Health Now. R.C.P., London.

Russell, M. A. H., Cole, P. V., and Brown, E., (1973a). Absorption by non-smokers of carbon monoxide from room air polluted by tobacco smoke. Lancet, 1, 576-579.

- Wilson, C., Cole, P. V., Idle, M., and Feyerabend, C. (1973b). Comparison of increases in carboxyhaemoglobin after smoking 'extra-mild' and 'non-mild' cigarettes. Lancet, 2, 687-690.

Shields, C. E. (1971). Elevated carbon monoxide levels from smoking in blood donors. Transfusion, 11, 89-93.

Wynder, E. L. and Hoffmann, D. (1967). Tobacco and tobacco smoke. Studies in Experimental Carcinogenesis. Academic Press, New York.

Received for publication 5 June 1974

Accepted for publication 13 August 1974 